\title{
Transitioning to Del Nido cardioplegia for all-comers: the next switching gear?
}

\author{
Mohamed Marzouk', Valerie Lafreniere-Bessi', Stephanie Dionne', Serge Simard², Christian Pigeon', \\ François Dagenais ${ }^{1}$, Niv $\mathrm{Ad}^{3}$ and Frederic Jacques ${ }^{1 *}$ (D)
}

\begin{abstract}
Background: Exclusive use of Del Nido cardioplegia administration in all adult patients undergoing cardiac surgery has been studied for operative, postoperative and myocardial protection outcomes.

Methods: From November 2016 to October 2017, Del Nido cardioplegia was used in 131 consecutive patients (DN group). Using a propensity score, DN group was compared to 251 patients having received intermittent cold blood cardioplegia (CB group).

Results: Preoperative characteristics were similar in DN and CB groups. Operative outcomes were statistically different ( $p<0.0001$ ): cardiopulmonary bypass (CPB) time (DN 105.9 $\pm 46.5, C B 131.2 \pm 38.8$ ); aortic cross-clamp time (DN 80.8 \pm 35.5, CB 102.2 \pm 31.3 ); operative time (DN 203.1 \pm 65.0, CB 241.5 \pm 54.7 ); total cardioplegia volume (DN $1328 \pm 879$, CB $3773 \pm 1226$ ); and peak glycemia on CPB (DN 8.2 \pm 2.3, CB $9.0 \pm 1.8$ ). No statistical differences were noted in intensive care unit stay, hospital stay and hospital death. Myocardial protection outcomes were similar: discharge left ventricular ejection fraction (DN $52 \pm 11, C B 51 \pm 10$ ); Troponin levels at the end of the surgery (DN $871 \pm 1623$, CB $1958 \pm 854$ ), day 1 (DN $853 \pm 1139$, CB $993 \pm 8234$ ) and day 4 (DN $442 \pm 540$, CB $463 \pm 317$ ).
\end{abstract}

Conclusion: Del Nido cardioplegia use in all adult cardiac surgeries is associated with improved surgical efficiency. The design of larger trials including adults combined cardiac procedures and emergencies is needed.

\section{Background}

Myocardial protection is the cornerstone of cardiac surgery [1]. The wide spectrum of strategies for myocardial protection ranges from the beating heart to diastolic arrest with cardioplegia. Cardioplegic arrest has been the preferred method of myocardial protection in most centers [2]. The ideal cardioplegia solution and administration regimen is still to be found [3].

Del Nido cardioplegia, extensively used in pediatric cardiac surgery, provides a bloodless quiescent operative field for a longer period than other cardioplegia solutions $[4,5]$. This may improve the surgical flow and the patient outcomes.

\footnotetext{
* Correspondence: frederic.jacques@criucpq.ulaval.ca

${ }^{1}$ Service of Cardiac Surgery, Institut universitaire de cardiologie et de pneumologie de Québec-IUCPQ, Université Laval, Quebec City, QC G1V 4G5, Canada

Full list of author information is available at the end of the article
}

In the last decade, Del Nido cardioplegia was gradually integrated into adult cardiac surgery surgical practice. Nevertheless, concerns were raised for use its use in the acquired cardiovascular disease population, partly because safety and efficacy data is missing [3]. So far, a number of small reports focused on a narrow portion of the practice and have been reassuring: 1) adult congenital [6], primary valve procedure [7-11], iterative valvular procedure [12], primary CABG [13-15], iterative CABG [16], and combined CABG and valvular procedures $[17,18]$.

This study reports the transition to Del Nido cardioplegia use among all adult cardiac surgical patients. Del Nido cardioplegia was compared to intermittent cold blood cardioplegia in terms of operative, postoperative as well as myocardial protection outcomes.

(c) The Author(s). 2020 Open Access This article is licensed under a Creative Commons Attribution 4.0 International License, which permits use, sharing, adaptation, distribution and reproduction in any medium or format, as long as you give appropriate credit to the original author(s) and the source, provide a link to the Creative Commons licence, and indicate if changes were made. The images or other third party material in this article are included in the article's Creative Commons licence, unless indicated otherwise in a credit line to the material. If material is not included in the article's Creative Commons licence and your intended use is not permitted by statutory regulation or exceeds the permitted use, you will need to obtain permission directly from the copyright holder. To view a copy of this licence, visit http://creativecommons.org/licenses/by/4.0/ The Creative Commons Public Domain Dedication waiver (http://creativecommons.org/publicdomain/zero/1.0/) applies to the data made available in this article, unless otherwise stated in a credit line to the data. 


\section{Methods}

\section{Patient selection}

From November 2016 to October 2017, Del Nido cardioplegia was used in 131 consecutive patients ( $\mathrm{DN}$ group) and compared using a propensity score to 251 patients who had received intermittent cold blood cardioplegia (CB group) and operated during the immediate period prior. All patients were operated by one surgeon (FJ). All cases were included in the study with no exception.

\section{Cardioplegia administration In the CB group}

Cold blood cardioplegia was administrated at $4{ }^{\circ} \mathrm{C}$ in antegrade and/or retrograde. Oxygenated blood from patient was withdrawn ( $1 \mathrm{~L})$ after CBP start. An addition of $200 \mathrm{meq} / 100 \mathrm{~mL}$ of $\mathrm{KCl}$ with $75 \mathrm{mg} / 100 \mathrm{~mL}$ of Magnesium and $50 \mathrm{mg}$ of Lidocaine for each $600 \mathrm{~mL}$ of cardioplegia solution was added. A volume of $600 \mathrm{~mL}$ of cold blood solution was delivered for the induction dose. Maintenance doses were given every $15-20$ min with a volume of $300 \mathrm{~mL}$ and half of the components of the induction solution. A "hot-shot" reperfusion dose before unclamping the aorta. Moderate systemic hypothermia reached $32{ }^{\circ} \mathrm{C}$ in isolated aortic valve replacement and in coronary bypass grafting (CABG) with less than 3 distal anastomoses, whereas a temperature of $30{ }^{\circ} \mathrm{C}$ was reached in other cases.

\section{In the DN group}

Del Nido cardioplegia was delivered at $4{ }^{\circ} \mathrm{C}$ with a $20 \%$ blood mixture as described by Matte et al [4]. Diastolic arrest was achieved with $1 \mathrm{~L}$ antegrade administration, if not, retrograde administration was used in adjunct. Redosing was performed with aortic cross-clamp time greater than $90 \mathrm{~min}$; with $500 \mathrm{~mL}$ or $1000 \mathrm{~mL}$, depending on the expected remaining surgical time. "Hot-shot" was not given in this group. All patients were put under moderate or deep hypothermia to balance the increase interval-redosing period.

Pericardial ice sludge was not used as this myocardial protection strategy is also linked to diaphragm dysfunction in obese or chronic obstructive pulmonary disease patients [19].

\section{Statistical analysis}

The representative measures use standard descriptive statistics to describe the data; absolute and relative frequencies for categorical variables and mean \pm standard deviation (SD) or median with interquartile range for continuous data according to the variable distribution. Statistical significance of differences between unmatched patient groups was tested using the Fisher's exact test for categorical variables; the Student's t-test or the Wilcoxon rank-sum test was performed for continuous variables. Using the residuals from the one-way statistical modeling of continuous variables, the normality assumption was verified with the Shapiro-Wilk test and the Brown and Forsythe's variation of Levene's test statistic was used to verify the homogeneity of variances.

A continuous propensity score analysis was performed. The likelihood of having a Del Nido cardioplegia was calculated for each patient by use of a logistic regression analysis that identified variables independently associated with Del Nido cardioplegia and the outcome. Variables included in the logistic regression analysis were the ones reported in the baseline characteristics table. Continuous variables were checked for the assumption of linearity in the logit and the graphical representations suggesting linear relationships. The variables were selected only if they maximized the within sample correct prediction rates. Interactions between variables were allowed only if it was supported clinically and statistically $(p<0.20)$. After model building, to assess the goodness-of-fit of the model, the HosmerLemeshow test was performed, resulting with the statistic of Chi-Square $=4.08$ with $\mathrm{df}=7$ and $p=0.7700$, indicating that the final model fitted quite well [20]. Propensity scores were finally developed based on all this covariates: atrial fibrillation, stroke, unstable angina, surgical categories. None of them are continuous variables. Thereafter, matched set on the propensity score without replacement of case and control subjects (many-to many or full matching) was performed using the Greedy matching algorithm to provide power to the propensity score. A 1:1 match yielded similar results but with less confidence (results not shown). Full matching involved the formation of strata, consisting of either one case subject (Del Nido cardioplegia) and at least one control subject or one control subject and at least one Del Nido cardioplegia subject. Subject with a Del Nido cardioplegia procedure were considered sequentially. Best match are case subjects matched to control subjects whose score equals that of the treated subjects to at least the sixth digit. When all matches at the sixth digit are exhausted, the process begins again until matches are performed on the first digit of the propensity score. At the end, if a treated subject cannot be matched to any subject of the other group on the first digit of the propensity score, then the subject is discarded from the matched analysis. At the sixth digit, 130 out of Del Nido cardioplegia patients (99.2\%) were fully matched to 228 intermittent cold blood cardioplegia patients (13 stratifications). After full matching, statistical analyses used a weighting approach, considering the clustering of subjects within each stratification. Del Nido cardioplegia subjects received a weight of 1 . Intermittent cold blood cardioplegia individuals in stratification received a weight proportional to case subjects divided by the number of Del Nido cardioplegia subject in the strata. The sum of the intermittent cold blood cardioplegia subject weights was scaled to equal the total number of matched Del Nido cardioplegia subjects (130). Continuous variables were 
expressed as weighted mean \pm SD. Categorical variables were expressed using proportions and analysed with a linear model and a logit link function adjusted for stratification (blocking factor) and weight [21].

To compare observed versus predicted means of length of stay and intensive care unit (ICU) length of stay during November 1st 2016 and November 1st 2017, a linear regression model with quarterly values as the only predictor was used to model the means observed between February 1st 2015 and August 1st 2016. The statistical models were used to predict quarterly the mean values for the periods 2016-2017.

Statistical significance was present when the two-tailed $p$ value $<0.05$. Analyses were performed using SAS version 9.4 (SAS Institute Inc., Cary, NC). The institutional research ethics board approved the study.

\section{Results}

\section{Patient population}

Demographics of all-comer patients are detailed in Table 1. Preoperative clinical characteristics were similar except for prior to matching, there were more cases with history of atrial fibrillation or redo surgeries in DN group and there were more cases with severe angina or non-elective surgeries in CB group. The proportion of patients with left ventricular ejection fraction (LVEF) less than $35 \%$ was $7.8 \%$ in DN group and $9.6 \%$ in $\mathrm{CB}$ group $(p=0.62)$. The LV mass index was $96 \pm 29 \mathrm{~mm}$ in the DN group and $97 \pm 22 \mathrm{~mm}$ in the $\mathrm{CB}$ group ( $p=$ 0.69 ). Moderate or severe aortic insufficiency was reported in $8.5 \%$ of patients in DN group and in $7.4 \%$ of patients in CB group $(p=0.74)$. Surgical procedures are outlined in Table 2. Matched groups did not show any significant difference in terms of types of procedure. Six cases of aortic dissections were included, two of which were done in $\mathrm{DN}$ group.

\section{Operative}

Operative characteristics and CBP data are described in Table 3. Surgical times were shorter in DN group $(p<$ $0.0001)$. Increased statistical significance was found with CABG and combined procedures (CABG+ valves) and to a lesser degree with valve only procedures. Valve only procedures had greater statistical impact for time spared

Table 1 Preoperative patient characteristics

\begin{tabular}{|c|c|c|c|c|c|c|}
\hline & \multirow[b]{2}{*}{$\begin{array}{l}\mathrm{DN}(n=131) \\
\text { No.(\%) or mean } \pm \text { SD(MED) }\end{array}$} & \multicolumn{3}{|l|}{ UNMATCHED } & \multicolumn{2}{|l|}{ MATCHED } \\
\hline & & $\begin{array}{l}\text { CB }(n=251) \\
\text { No. }(\%) \text { or mean } \pm \text { SD(MED) }\end{array}$ & $p$ value & $\begin{array}{l}\text { DN }(n=130) \\
\% \text { or mean } \pm \text { SD }\end{array}$ & $\begin{array}{l}C B(n=228) \\
\% \text { or mean } \pm \text { SD }\end{array}$ & SMD \\
\hline Age (years) & $65.8 \pm 12.9(68)$ & $65.8 \pm 11.3(67)$ & 0.99 & $65.8 \pm 12.9$ & $65.1 \pm 9.2$ & 0.06248 \\
\hline Sex $F$ & $35(26.7)$ & $73(29.1)$ & 0.71 & 26.2 & 32.7 & -0.14296 \\
\hline body mass index $\left(\mathrm{kg} / \mathrm{m}^{2}\right)$ & $28.4 \pm 5.7$ & $29.0 \pm 5.8$ & 0.35 & $28.4 \pm 5.8$ & $28.9 \pm 4.6$ & -0.09552 \\
\hline Diabetes & $37(28.2)$ & $34(33.5)$ & 0.35 & 28.5 & 28.8 & -0.00664 \\
\hline Hypertension & $92(70.2)$ & 192(76.5) & 0.21 & 70.0 & 72.5 & -0.05526 \\
\hline COPD & $21(16.9)$ & 29(11.6) & 0.26 & 15.4 & 14.8 & 0.01676 \\
\hline Stroke & $5(3.8)$ & $21(8.4)$ & 0.13 & 3.1 & 3.1 & 0 \\
\hline CKD and or dialysis & $9(6.9)$ & $10(4.0)$ & 0.22 & 6.2 & 4.5 & 0.07560 \\
\hline peripheral vascular disease & $9(6.9)$ & $31(12.4)$ & 0.11 & 6.9 & 11.3 & -0.15343 \\
\hline Atrial Fibrillation & $38(29)$ & $43(17.1)$ & 0.008 & 28.5 & 28.5 & 0 \\
\hline NYHA III or IV/IV & $34(26.0)$ & $65(25.9)$ & 1.0 & 26.2 & 31.1 & -0.10854 \\
\hline Angina CCS $>3$ & $30(22.9)$ & 83(33.1) & 0.04 & 23.1 & 20.6 & 0.06053 \\
\hline Unstable angina & $10(7.6)$ & $51(20.3)$ & 0.0011 & 7.7 & 7.7 & 0 \\
\hline Non-elective & 15(11.5) & $58(23.1)$ & 0.006 & 11.5 & 14.8 & -0.09777 \\
\hline Redo & 19(14.5) & $18(7.2)$ & 0.02 & 13.9 & 12.2 & 0.05048 \\
\hline LVEF & $54 \pm 11$ & $53 \pm 11$ & 0.62 & $54 \pm 11$ & $53 \pm 9$ & 0.09950 \\
\hline LVEF $<50 \%$ & $27(20.9)$ & $59(23.6)$ & 0.60 & 21.1 & 23.4 & -0.05532 \\
\hline LVEF $<35 \%$ & $10(7.8)$ & 20(8.0) & 1.0 & 7.8 & 9.6 & -0.06390 \\
\hline Aortic Insufficiency $>2 / 4$ & $11(8.5)$ & $19(7.7)$ & 0.84 & 8.5 & 7.4 & 0.04067 \\
\hline LV Mass Index & $96 \pm 29(92)$ & $96 \pm 29(92)$ & 0.95 & $96 \pm 29$ & $97 \pm 22$ & -0.03885 \\
\hline Parsonnet Score & $2.9 \pm 3.7$ & $2.7 \pm 3$ & 0.59 & $2.7 \pm 3.4$ & $2.9 \pm 2.3$ & -0.06890 \\
\hline Euroscore II & $5.2 \pm 7.1$ & $5.3 \pm 7.1$ & 0.92 & $5.1 \pm 7.0$ & $5.8 \pm 5.5$ & -0.11120 \\
\hline
\end{tabular}

CCS Canadian Cardiovascular Society, CKD chronic kidney disease (creatinine $>2 \mathrm{mg} / \mathrm{dl}$ ), COPD chronic obstructive lung disease, $L V E F$ left ventricular ejection fraction, NYHA New York Heart Association 
Table 2 Surgical categories

\begin{tabular}{|c|c|c|c|c|c|c|}
\hline & \multirow[b]{2}{*}{$\begin{array}{l}\text { DN }(n=131) \\
\text { No.(\%) }\end{array}$} & \multicolumn{3}{|l|}{ UNMATCHED } & \multicolumn{2}{|l|}{ MATCHED } \\
\hline & & $\begin{array}{l}C B(n=251) \\
\text { No.(\%) }\end{array}$ & $p$ value & $\begin{array}{l}\text { DN }(n=130) \\
\%\end{array}$ & $\begin{array}{l}C B(n=228) \\
\%\end{array}$ & SMD \\
\hline Isolated CABG & $62(47.3)$ & $145(57.8)$ & 0.006 & 47.7 & 58.8 & -0.22386 \\
\hline Valvular procedures & $29(22.1)$ & $27(10.8)$ & & 21.5 & 11.8 & 0.26262 \\
\hline CABG+Valvular procedures & 15(11.5) & $43(17.1)$ & & 11.5 & 14.5 & -0.08929 \\
\hline Others & 25(19.0) & $36(14.3)$ & & 19.2 & 14.9 & 0.11453 \\
\hline
\end{tabular}

with multiple compared to single valve procedures. Antegrade cardioplegia was administered for most cases except for aortic dissections. A retrograde route was used in $13.1 \%$ of surgeries in DN group and in $38.0 \%$ of surgeries in CB group $(p<0.0001)$. The total cardioplegia volume given during surgery in $\mathrm{DN}$ group was less than in CB group $(1328 \pm 879 \mathrm{~mL}$ vs $3773 \pm 1226 \mathrm{~mL}$, $\mathrm{p}<0.0001$ ). Defibrillation after unclamping the aorta was significantly lower in the DN group $(16.9 \%$ vs $32.4 \%, p=$ $0.01)$. The average peak blood sugar during CPB was lower in DN group $(8.2 \pm 2.3$ vs $9.0 \pm 1.8, p=0.001)$. The proportion of patient with a blood sugar higher than 10 $\mathrm{mmol} / \mathrm{L}$ at the end of $\mathrm{CPB}$ and receiving blood transfusions during $\mathrm{CPB}$ were similar in both groups.

\section{Postoperative}

Postoperative outcomes are shown in Table 4. DN and CB groups had similar outcomes including ICU length of stay, ventilation length, hospital length of stay as well as occurrence of stroke, renal failure, sternal infection, gastrointestinal complication, hepatic dysfunction, bleeding, transfusion rate and mortality. A linear relation was obtained for the ICU and hospital length of stays when accounting for different trimesters of cardioplegia use (Fig. 1). The data distribution obtained with Del Nido cardioplegia matched the distribution of cold blood cardioplegia. This shows that the improvement is not due to a change in practice or the effect of time.

\section{Myocardial protection}

Myocardial protection outcomes are described in Tables 5 and 6. DN and CB groups had similar postoperative LVEF, needs for inotropic drugs for low cardiac output, atrial and ventricular arrhythmias, and conduction abnormalities (Table 5). Postoperative Troponin T levels evolved differently in time between the two groups but there was not statistically significant difference (Table 6).

\section{Discussion}

The safeguard of cardiac surgery requires good myocardial protection and good "all other organ" protection. Intermittent cold blood cardioplegia is heart-safe but cumbersome. Minor changes in surgical flow and reduced times can impact mortality [5]. Del Nido cardioplegia has a safe record in pediatric cardiac surgery and has been used in many adult cardiac surgery centers for the last decade. Recent studies of selected adult population have demonstrated encouraging outcomes [6-18]. A transition from intermittent cold blood to Del Nido cardioplegia for all-comers seemed a potential way to improve surgical flow. The current study supports the routine use of Del Nido cardioplegia in all cases of adult cardiac surgery.

Myocardial protection concerns have been raised on the use of DN cardioplegia in adults and acquired cardiovascular disease patients. Use for diabetics with extensive microvascular disease and administration by a retrograde route have been debated $[15,16]$. The growing body of literature tends to refute these concerns. Myocardial protection results in DN group are superimposable to the ones in cold blood cardioplegia even with a patient population composed of $\sim 30 \%$ diabetics and $20 \%$ with poor left ventricular function. Indeed, in the postoperative period both groups had a LVEF around $50 \%$. Average Troponin T levels were lower but not statistically different unlike other reports $[8,14]$. A recently published study by Kim et al. [9] compared levels of Troponin I and creatine-kinase-MB in patients undergoing cardiac surgery with Del Nido or cold blood cardioplegia and showed lower levels of both enzymatic markers in patients having received Del Nido cardioplegia. The use of Del Nido cardioplegia could be better for the aged heart as suggested by rodent-based studies [22, 23]. This study lends supports to the use of Del Nido cardioplegia in adults.

\section{Operative outcomes}

Del Nido cardioplegia allows for minimal interruption during surgical procedures compared to cold blood cardioplegia. The mean aortic cross-clamp time in DN group requires no redosing. Taking into consideration the $2400 \mathrm{~mL}$ difference of total cardioplegia volume given between groups and an administration rate of 300 $\mathrm{mL} / \mathrm{min}$, Del Nido solution spares $8 \mathrm{~min}$ of aortic crossclamp time for the cardioplegia delivery itself. The releasing/regaining exposure time may account for the other 13 min of aortic cross-clamp spared. Del Nido cardioplegia use allows for sequence modifications to 
Table 3 Operative characteristics and cardiopulmonary bypass (CBP) data

\begin{tabular}{|c|c|c|c|c|c|c|}
\hline & \multirow[b]{2}{*}{$\begin{array}{l}\text { DN }(n=131) \\
\text { No.(\%) or mean } \pm \text { SD }\end{array}$} & \multicolumn{3}{|l|}{ UNMATCHED } & \multicolumn{2}{|l|}{ MATCHED } \\
\hline & & $\begin{array}{l}C B(n=251) \\
\text { No.(\%) or mean } \pm S D\end{array}$ & $p$ value & $\begin{array}{l}\text { DN }(n=130) \\
\% \text { or mean } \pm S D\end{array}$ & $\begin{array}{l}C B(n=228) \\
\% \text { or mean } \pm S D\end{array}$ & $p$ value \\
\hline Cross-Clamp Time (min) & $81.1 \pm 35.6$ & $99.4 \pm 41.2$ & $<0.0001$ & $80.8 \pm 35.5$ & $102.2 \pm 31.3$ & $<0.0001$ \\
\hline Isolated CABG & $64.6 \pm 19.2$ & $80.1 \pm 24.1$ & $<0.0001$ & $65.9 \pm 4.6$ & $85.8 \pm 4.6$ & $<0.0001$ \\
\hline Valvular procedures & $76.8 \pm 30.3$ & $82.0 \pm 31.2$ & 0.60 & $88.8 \pm 17.9$ & $110.3 \pm 17.9$ & 0.02 \\
\hline CABG+Valvular procedures & $104.3 \pm 31.0$ & $134.8 \pm 41.4$ & 0.05 & $106.7 \pm 7.7$ & $146.0 \pm 7.7$ & 0.001 \\
\hline Others & $95.3 \pm 43.1$ & $120.7 \pm 45.6$ & 0.002 & $113.8 \pm 14.3$ & $128.9 \pm 14.0$ & 0.24 \\
\hline Isolated valve & $\begin{array}{l}91.9 \pm 41.4(85) \\
N=50 / 61\end{array}$ & $\begin{array}{l}122.8 \pm 43.2(123) \\
N=79 / 91\end{array}$ & $<0.0001$ & $104.3 \pm 9.4$ & $127.9 \pm 9.2$ & 0.0005 \\
\hline Multiple valve & $\begin{array}{l}126.7 \pm 31.7(120) \\
N=11 / 61\end{array}$ & $\begin{array}{l}174.0 \pm 43.2(179) \\
N=12 / 91\end{array}$ & 0.0074 & $126.7 \pm 10.9$ & $167.6 \pm 11.6$ & 0.0179 \\
\hline CBP time (min) & $106.3 \pm 46.6$ & $125.1 \pm 49.6$ & 0.0004 & $105.9 \pm 46.5$ & $131.2 \pm 38.8$ & $<0.0001$ \\
\hline Isolated CABG & $81.6 \pm 22.0$ & $99.2 \pm 28.0$ & 0.0001 & $84.9 \pm 7.6$ & $109.3 \pm 7.6$ & $<0.0001$ \\
\hline Valvular procedures & $104.3 \pm 34.1$ & $113.1 \pm 49.3$ & 0.51 & $112.4 \pm 16.1$ & $136.7 \pm 16.1$ & 0.03 \\
\hline CABG+Valvular procedures & $127.8 \pm 5.5$ & $164.0 \pm 47.3$ & 0.04 & $132.4 \pm 10.0$ & $177.3 \pm 10.0$ & 0.001 \\
\hline Others & $127.6 \pm 58.3$ & $153.8 \pm 52.4$ & 0.008 & $149.3 \pm 11.8$ & $166.3 \pm 11.8$ & 0.31 \\
\hline Isolated valve & $\begin{array}{l}124.0 \pm 54.1(118) \\
N=50 / 61\end{array}$ & $\begin{array}{l}154.1 \pm 51.7(152) \\
N=79 / 91\end{array}$ & 0.0020 & $137.7 \pm 11.2$ & $160.3 \pm 11.0$ & 0.0089 \\
\hline Multiple valve & $\begin{array}{l}157.7 \pm 43.3(146) \\
N=11 / 61\end{array}$ & $\begin{array}{l}210.6 \pm 46.4(206) \\
N=12 / 91\end{array}$ & 0.0104 & $157.7 \pm 12.9$ & $205.4 \pm 13.7$ & 0.0192 \\
\hline Length of surgery 'SkinSkin' (min) & $204.0 \pm 65.5$ & $236.4 \pm 67.2$ & $<0.0001$ & $203.1 \pm 65.0$ & $241.5 \pm 54.7$ & $<0.0001$ \\
\hline Isolated CABG & $178.5 \pm 32.7$ & $212.0 \pm 46.7$ & $<0.0001$ & $183.7 \pm 8.2$ & $224.2 \pm 8.2$ & $<0.0001$ \\
\hline Valvular procedures & $198.8 \pm 63.3$ & $211.4 \pm 83.7$ & 0.59 & $205.7 \pm 25.3$ & $229.3 \pm 25.3$ & 0.19 \\
\hline CABG+Valvular procedures & $238.0 \pm 94.5$ & $270.8 \pm 63.0$ & 0.25 & $235.3 \pm 15.2$ & $286.2 \pm 15.2$ & 0.02 \\
\hline Others & $225.2 \pm 75.9$ & $267.0 \pm 73.9$ & 0.002 & $251.2 \pm 15.2$ & $293.4 \pm 15.2$ & 0.05 \\
\hline Isolated valve & $\begin{array}{l}224.3 \pm 85.6(215) \\
N=50 / 61\end{array}$ & $\begin{array}{l}262.5 \pm 76.1(255) \\
N=79 / 91\end{array}$ & 0.0092 & $240.0 \pm 16.5$ & $271.2 \pm 16.2$ & 0.0200 \\
\hline Multiple valve & $\begin{array}{l}246.4 \pm 53.1(230) \\
N=11 / 61\end{array}$ & $\begin{array}{l}304.9 \pm 95.0(324) \\
N=12 / 91\end{array}$ & 0.0861 & $246.4 \pm 22.3$ & $299.9 \pm 23.7$ & 0.1143 \\
\hline Retrograde cardioplegia & 17(13.0) & $76(31.3)$ & 0.0001 & 13.1 & 38.0 & $<0.0001$ \\
\hline Antegrade cardioplegia & 130(99.2) & 249(99.2) & 1.0 & 99.2 & 98.9 & 0.81 \\
\hline Total cardioplegia dose $(\mathrm{mL})^{a}$ & $1331 \pm 876$ & $3719 \pm 1571$ & $<0.0001$ & $1328 \pm 879$ & $3773 \pm 1226$ & $<0.0001$ \\
\hline Minimal temperature on $\mathrm{CPB}\left({ }^{\circ} \mathrm{C}\right)$ & $30.4 \pm 3.2$ & $31.1 \pm 3.4$ & 0.005 & $30.5 \pm 3.2$ & $30.8 \pm 2.8$ & 0.28 \\
\hline Glucose peak on CPB (mmol/l) & $8.2 \pm 2.3$ & $8.8 \pm 2.4$ & 0.011 & $8.2 \pm 2.3$ & $9.0 \pm 1.8$ & 0.001 \\
\hline Glucose end CBP (mmol/l) & $8.4 \pm 2.6$ & $8.2 \pm 2.4$ & 0.10 & $8.4 \pm 2.7$ & $8.9 \pm 1.9$ & 0.06 \\
\hline Glucose $>10$ end of CBP $(\mathrm{mmol} / \mathrm{l})$ & $24(20.0)$ & $62(26.2)$ & 0.24 & 20.2 & 24.2 & 0.46 \\
\hline Transfusion in OR & 48(36.6) & 104(41.4) & 0.38 & 36.2 & 42.7 & 0.27 \\
\hline Intraoperative Defibrillation & $21(16)$ & $69(27.5)$ & 0.02 & 16.9 & 32.4 & 0.01 \\
\hline
\end{tabular}

${ }^{a}$ All cardioplegia volumes shown in this text and tables are the total volume given to the patient, including the crystalloid and the blood components

optimise surgical flow. Altogether, this reflects a $20 \%$ shorter aortic cross-clamp time in DN group. Other studies showed similar results in terms of length of operative times $[8,14,17]$. Ad et al. published the only randomized controlled trial on the use of Del Nido cardioplegia in adult showing consistent results with these findings without reaching statistical significance [18]. The most important gain in terms of spared time comes from the procedures with the most steps such as for CABG and combined procedures (CABG + valves). Exploratory data on single and multiple valves (Table 3) suggests that there is the most benefit for multiple valves. This study is underpowered to prove so but it is likely that patients who would benefit the most from Del Nido cardioplegia would be the ones with more complex surgeries. 
Table 4 Postoperative outcomes. ICU: intensive care unit; SD: standard deviation

\begin{tabular}{|c|c|c|c|c|c|c|}
\hline & \multirow[b]{2}{*}{$\begin{array}{l}\text { DN }(n=131) \\
\text { No. }(\%) \text { or mean } \pm \text { SD(MED) }\end{array}$} & \multicolumn{3}{|l|}{ UNMATCHED } & \multicolumn{2}{|l|}{ MATCHED } \\
\hline & & $\begin{array}{l}C B(n=251) \\
\text { No. }(\%) \text { or mean } \pm \text { SD }(M E D)\end{array}$ & $p$ value & $\begin{array}{l}\text { DN }(n=130) \\
\% \text { or mean } \pm \text { SD }\end{array}$ & $\begin{array}{l}C B(n=228) \\
\% \text { or mean } \pm S D\end{array}$ & $p$ value \\
\hline ICU stay (days) & $1.9 \pm 1.9$ & $1.9 \pm 2.5$ & 0.91 & $1.9 \pm 1.8$ & $2.0 \pm 2.1$ & 0.64 \\
\hline Length of ventilation (h) & $9.4 \pm 27.3(4.4)$ & $9.1 \pm 19.6(4.3)$ & 0.90 & $9.5 \pm 27.4$ & $8.9 \pm 13.1$ & 0.83 \\
\hline Intubation $>48 \mathrm{~h}$ & $4(3.1)$ & $9(3.6)$ & 1.0 & 3.1 & 3.6 & 0.83 \\
\hline Length of stay (days) & $8.2 \pm 5.7$ & $8.1 \pm 5.3$ & 0.82 & $8.0 \pm 5.4$ & $8.5 \pm 4.3$ & 0.39 \\
\hline Stroke & $3(2.3)$ & $5(2.0)$ & 1.0 & 2.3 & 3.7 & 0.52 \\
\hline Deep sternal wound infection & $3(2.3)$ & $2(0.8)$ & 0.34 & 2.3 & 1.0 & 0.57 \\
\hline Dialysis & $4(3.1)$ & $5(2.0)$ & 0.50 & 3.1 & 2.8 & 0.89 \\
\hline Gastrointestinal complication & $5(3.8)$ & $13(5.2)$ & 0.62 & 3.1 & 6.6 & 0.20 \\
\hline Hepatic Dysfunction & $3(2.3)$ & $11(4.4)$ & 0.40 & 2.3 & 5.8 & 0.17 \\
\hline Reoperation for Bleeding & $8(6.1)$ & $15(6.0)$ & 1.0 & 6.2 & 4.7 & 0.61 \\
\hline In hospital transfusion & $90(68.7)$ & 173(68.9) & 1.0 & 68.5 & 68.8 & 0.95 \\
\hline In hospital Mortality & $3(2.3)$ & $9(3.6)$ & 0.76 & 2.3 & 5.1 & 0.24 \\
\hline
\end{tabular}

Interestingly, DN group had lower total cardioplegia volume and blood sugar level, although the clinical relevance of these findings remains inconclusive. The total Del Nido cardioplegia volume given was one third of the volume of cold blood cardioplegia but did not translate into fewer transfusions such as reported by Kim et al. [9]. It is possible that the reduction in cardioplegia volume in combination with the more physiologic nature of the cardioplegic solution may contribute to myocardial protection by reducing myocardial edema [24]. This is reported with the use of microplegia solutions [25]. Of possible benefit for diabetic patients, $\mathrm{CPB}$ peak glucose level was lower in DN group possibly allowing for easier blood glucose management during surgery [15]. Mick et al. reported similar findings when comparing Del Nido to Buckberg cardioplegia [10]. Glycemic control is a major concern in cardiac surgery. High glycemia is related to higher risk of complications such as mediastinitis while lower glycemia can lead to poor neurological control [15]. This study was not designed to conclude if a better glycemic control with Del Nido cardioplegia translates into a lower rate of these rare complications.
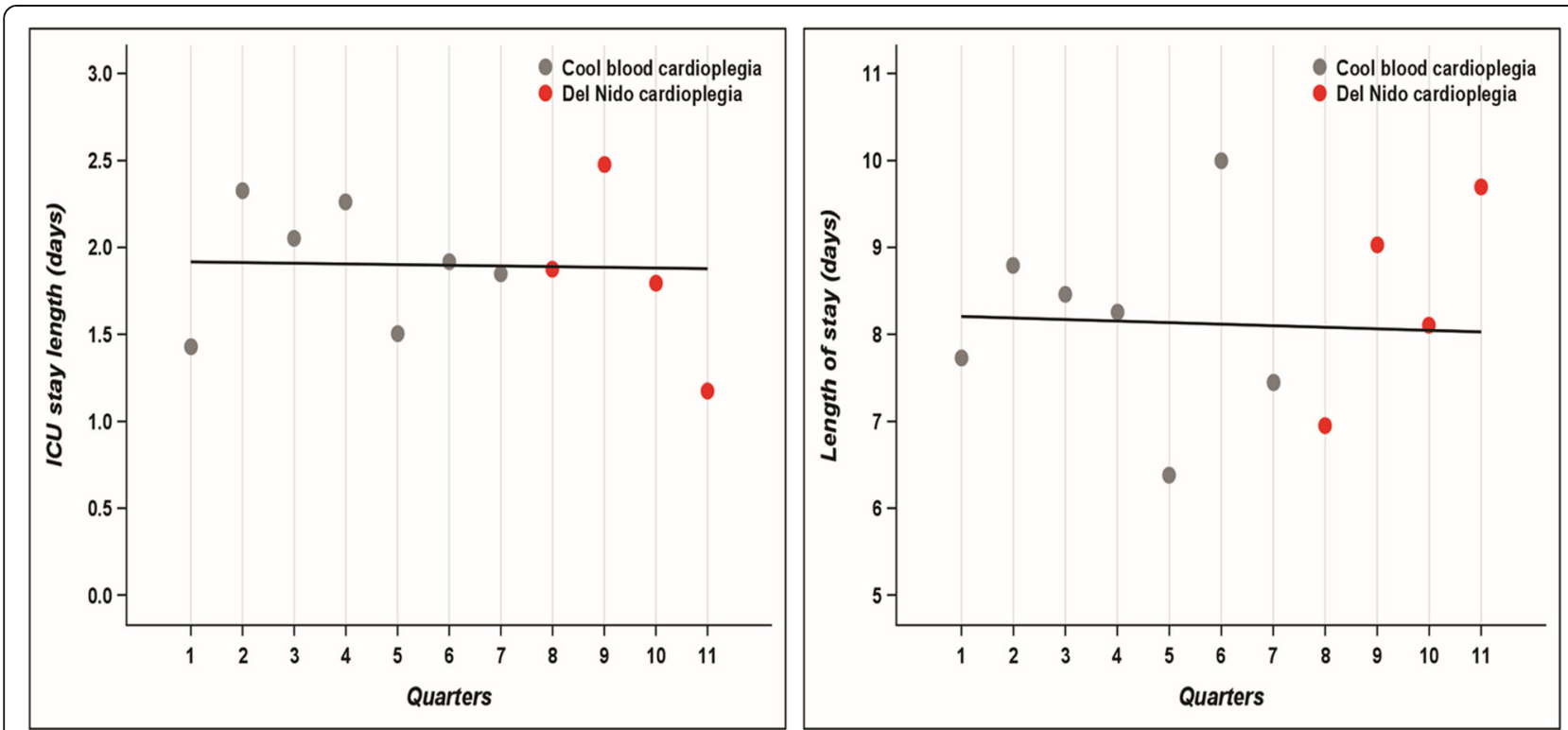

Fig. 1 Linear regression of intensive care unit and hospital length of stays in days for cold blood cardioplegia obtained during 2015-2016 trimesters (quarters) to predict quarterly values for the 2016-2017 period 
Table 5 Myocardial protection outcomes

\begin{tabular}{|c|c|c|c|c|c|c|}
\hline & \multirow[b]{2}{*}{$\begin{array}{l}\mathrm{DN}(\mathrm{n}=131) \\
\text { No.(\%) or mean } \pm \text { SD }\end{array}$} & \multicolumn{3}{|l|}{ UNMATCHED } & \multicolumn{2}{|l|}{ MATCHED } \\
\hline & & $\begin{array}{l}C B(n=251) \\
\text { No. }(\%) \text { or mean } \pm S D\end{array}$ & $p$ value & $\begin{array}{l}\text { DN }(n=130) \\
\% \text { or mean } \pm S D\end{array}$ & $\begin{array}{l}C B(n=228) \\
\% \text { or mean } \pm S D\end{array}$ & $p$ value \\
\hline$\overline{\operatorname{LVEF}(\%)}$ & $52 \pm 11$ & $50 \pm 12$ & 0.22 & $52 \pm 11$ & $51 \pm 10$ & 0.37 \\
\hline Needing Inotropes for low cardiac outflow & $11(8.4)$ & $17(6.8)$ & 0.54 & 8.5 & 9.2 & 0.84 \\
\hline Postop Atrial Flutter & $34(26.0)$ & $42(16.7)$ & 0.04 & 25.4 & 19.0 & 0.43 \\
\hline Atrial Fibrillation de Novo & $35(26.7)$ & $74(29.5)$ & 0.63 & 26.9 & 26.5 & 0.93 \\
\hline Postop VTNF & $8(6.1)$ & $7(2.8)$ & 0.16 & 5.4 & 4.1 & 0.63 \\
\hline Conduction Abnormalities & $6(4.6)$ & $13(5.2)$ & 1.0 & 4.6 & 4.6 & 1.0 \\
\hline Pacemaker & $5(3.8)$ & $9(3.6)$ & 1.0 & 3.9 & 4.5 & 0.80 \\
\hline
\end{tabular}

LVEF Left ventricular ejection fraction, VF ventricular fibrillation, $V T$ ventricular tachycardia

A strict glucose management protocol was not used, although local clinical policies regarding glycemic control are well disseminated.

\section{Postoperative}

Sorabella et al. [12] and Yerebakan et al. [14] studied Del Nido cardioplegia use in redo aortic valve surgery and isolated CABG after acute myocardial infarction, respectively; shorter in-hospital length of stay was reported. In this all-comer cohort, it is likely that this benefit can be offset by factors such as having one fifth of patients with preoperative LVEF $<50 \%$. Interestingly, around one tenth of the patients in both groups had a LVEF $<35 \%$ for whom a mortality of $1 \%$ was found in $\mathrm{CB}$ group and no deaths in DN group. In this subset of patients, an increase in LVEF of $\geq 10 \%$ was seen postoperatively in $20 \%$ of patients from CB group and $40 \%$ of patients DN group, while no decrease in LVEF were found. Ideal myocardial protection strategy in this subgroup of patients is still to be found. Patients in both cardioplegia groups had similar surgical risks preoperatively as calculated by Parsonnet score and Euroscore II. This study reports no significant differences in term of complications between both cardioplegias and the observed mortality was lower than predicted by risks scores in both groups. This demonstrates that the absence of difference between the two groups is not based on patient selection or a learning curve effect. Similarly, the regression model used to predict the length of stay if cold blood cardioplegia was continued in time is superimposable to the actual data obtained with Del Nido cardioplegia. This supposes that the overall management of patients remains the same over the course of the study. Finally, even if the study was not powered to detect significant differences in rare events it is interesting to note that major gastrointestinal and hepatic complications appeared less frequent in DN group. These rare complications could be significantly decreased in larger cohorts of Del Nido cardioplegia with shorter CPB duration.

\section{Limitations}

This study is limited by its retrospective, observational and single-surgeon single-institution design. The study includes heterogenous patients, although the proportion of types of procedures was matched. Although there is an historical bias with both cohorts being sequential, the clinical significance should be limited. From a clinical standpoint, lidocaine was administered in both groups since the "local cold blood recipe" contains lidocaine.

\section{Conclusions}

Altogether, Del Nido cardioplegia appears safe for use in all adult cardiac surgery cases. The surgical strategy allowed by the use of Del Nido cardioplegia seems to

Table 6 T Troponin evolutions: post-operative values

\begin{tabular}{|c|c|c|c|c|c|c|}
\hline & & UNMATCHED & & & MATCHED & \\
\hline T Troponin (ng/L) & $\begin{array}{l}\mathrm{DN}(n=131) \\
\text { mean } \pm S D\end{array}$ & $\begin{array}{l}C B(n=251) \\
\text { mean } \pm S D\end{array}$ & $p$ value & $\begin{array}{l}\mathrm{DN}(\mathrm{n}=130) \\
\text { mean } \pm S D\end{array}$ & $\begin{array}{l}C B(n=228) \\
\text { mean } \pm S D\end{array}$ & $p$ value \\
\hline Day 0 & $872 \pm 1617$ & $906 \pm 1118$ & 0.81 & $871 \pm 1623$ & $958 \pm 854$ & 0.50 \\
\hline Day 1 & $860 \pm 1137$ & $933 \pm 1016$ & 0.52 & $853 \pm 1139$ & $993 \pm 823$ & 0.21 \\
\hline Day 2 & $677 \pm 1465$ & $613 \pm 686$ & 0.57 & $671 \pm 1469$ & $636 \pm 519$ & 0.77 \\
\hline Day 4 & $450 \pm 545$ & $461 \pm 483$ & 0.84 & $442 \pm 540$ & $463 \pm 317$ & 0.67 \\
\hline Maximum peak & $1186 \pm 2116$ & $1119 \pm 1243$ & 0.70 & $1182 \pm 2124$ & $1171 \pm 957$ & 0.95 \\
\hline
\end{tabular}


confer adequate myocardial protection and all other organ protection. This strategy is associated with decreased operative times compared to intermittent coldblood cardioplegia. Trials including large cohorts of patients with decreased ventricular function, diabetes and emergency surgeries are required.

\section{Abbreviations}

CABG: Coronary artery bypass grafting; CB: Cold blood;

CPB: Cardiopulmonary bypass; DN: Del Nido; ICU: Intensive care unit; KCl: Potassium chloride; L: Liter; LV: Left ventricle; LVEF: Left ventricle ejection fraction; SD: Standard deviation

\section{Acknowledgements}

None.

\section{Authors' contributions}

FJ, VLB, SD and SS contributed to the conception or design of the study. $V L B, S D$ and MM contributed to the acquisition, analysis or interpretation of data. FJ, VLB, SD and MM drafted the manuscript. CP, FD and NA critically and substantively revised and polished the manuscript. All authors read and approved the final manuscript.

\section{Funding}

This study received no funding.

\section{Availability of data and materials}

Complete data are available from the corresponding author upon request.

\section{Ethics approval and consent to participate}

This single-center retrospective study was approved by the Institutional Review Board of Institut de cardiologie et de pneumologie de Québec-Université Laval. As data is derived from a prospective anonymized database, individual consent was waived.

\section{Consent for publication}

Not applicable.

\section{Competing interests}

FJ is Associate Editor at BMC Cardiovascular Disorders.

\section{Author details}

${ }^{1}$ Service of Cardiac Surgery, Institut universitaire de cardiologie et de pneumologie de Québec-IUCPQ, Université Laval, Quebec City, QC G1V 4G5, Canada. ${ }^{2}$ Biostatistics, Institut universitaire de cardiologie et de pneumologie de Québec-IUCPQ, Université Laval, Québec, QC, Canada. ${ }^{3}$ Department of Cardiovascular and Thoracic Surgery, West Virginia University, Morgantown, W, USA.

Received: 12 December 2019 Accepted: 3 May 2020

Published online: 08 May 2020

\section{References}

1. Ovrum E, Tangen G, Tollofsrud S, Oystese R, Ringdal MA, Istad R. Cold blood versus cold crystalloid cardioplegia:a prospective randomised study of 345 aortic valve patients. Eur J Cardiothorac Surg. 2010;38:745-9.

2. Buckberg GD, Athanasuleas CL. Cardioplegia: solutions or Stategies? Eur J Cardiothorac Surg. 2016;50(5):787-91.

3. Ferguson $\mathrm{ZG}$, Yarborough $\mathrm{DE}$, Jarvis $\mathrm{BL}$, Sistino JJ. Evidence-based medicine and myocardial protection-where is the evidence? Perfusion. 2017;21:30-5.

4. Matte GS, del Nido PJ. History and use of del Nido cardioplegia solution at Boston Children's hospital. J Extra Corpor Technol. 2012;44(3):98-103.

5. Madhavan S, Chan SP, Tan WC, et al. Cardiopulmonary bypass time: every minute counts. J Cardiovasc Surg. 2018;59(2):274-8.

6. Charette K, Gerrah R, Quaegebeur J, et al. Single dose myocardial protection technique utilizing del Nido cardioplegia solution during congenital heart surgery procedures. Perfusion. 2012;27:98-103.

7. Vistarini N, Laliberté E, Beauchamp P, et al. Del Nido cardioplegia in the setting of minimally invasive aortic valve surgery. Perfusion. 2016;32:1-6.
8. Ziazadeh D, Mater R, Himelhoch B, et al. Single dose del Nido cardioplegia in minimally invasive aortic valve surgery. Semin Thorac Cardiovasc Surg. 2017;29(4):471-6.

9. Kim WK, Kim HR, Kim JB, et al. del Nido cardioplegia in adult cardiac surgery: beyond single-valve surgery. Interact Cardiovasc Thorac Surg. 2018; 27(1):81-7.

10. Mick SL, Robich MP, Houghtaling PL, et al. Del Nido versus Buckberg cardioplegia in adult isolated valve surgery. J Thorac Cardiovasc Surg. 2015; 149:626-36.

11. Luo H, Qi X, Shi H, et al. Single-dose del Nido cardioplegia used in adult minimally invasive valve surgery. J Thorac Dis. 2019;11(6):2373-82.

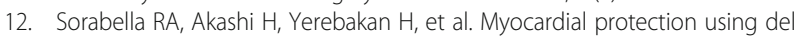
Nido cardioplegia solution in adult reoperative aortic valve surgery. J Card Surg. 2014;29:445-9.

13. Timek T, Willekes $C$, Hulme $\mathrm{O}$, et al. Propensity matched analysis of Del Nido Cardioplegia in adult coronary Aretry bypass grafting: initial experience with 100 consecutive patients. Ann Thorac Surg. 2016;101:2237-42.

14. Yerebakan $H$, Sorabella RA, Najjar M, et al. Del Nido cardioplegia can be safely administred in high risk coronary artery bypass grafting surgery after acute myocardial infarction: a propensity matched comparaison. J Cardiothorac Surg. 2014;9:141.

15. Sizekely A, Levin J, Miao Y. Impact of hyperglycemia on perioperative mortality after coronary artery bypass graft surgery. J Thorac Cardiovasc Surg. 2011;142:430-7.

16. Najjar M, George I, Akashi $\mathrm{H}$, et al. Feasibility and safety of continuous retrograde administration of Del Nido cardioplegia: a case series. J Cardiothoracic Surg. 2015;10:176

17. Hamad R, Nguyen A, Laliberte E, et al. Comparison of del Nido cardioplegia with blood cardioplegia in adult combined surgery. Innov. 2017;12:356-62.

18. Ad N, Holmes SD, Massimiano PS, Rongione AJ, Fornaresio LM, Fitzgerald D. The use of del Nido cardioplegia in adult cardiac surgery: a prospective randomized trial. J Thorac Cardiovasc Surg. 2017;155:1011-8.

19. Nazer Rl, Albarrati AM. Topical ice slush adversely affects sniff nasal inspiratory force after coronary bypass surgery. Heart Lung Circ. 2018;27(3): 371-6.

20. Hosmer DW, Lemeshow S. A goodness-of-fit test for the multiple logistric regression model. Commun Stat. 1980;A10:1043-69.

21. Hansen BB. Full matching in an observational study of coaching for the SAT. Im Stat Assoc. 2004:99:609-18.

22. Govindapillai A, O'Blenes S, Rose RA, Hua R, Hancock FC. Del Nido Cardioplegia provides superior myocardial protection for aged hearts. Can J Cardiol. 2013;29(10):S262-3.

23. O'Blenes SB, Friesen $\mathrm{CH}$, Ali A, Howlett S. Protecting the aged heart during cardiac surgery: the potential benefits of Del Nido cardioplegia. J Thorac Cardiovasc Surg. 2011;141(3):762-70.

24. Valooran GJ, Nair SK, Chandrasekharan K, Simon R, Dominic C. del Nido cardioplegia in adult cardiac surgery-scopes and concerns. Perfusion. 2016; 31(1):6-14.

25. Gong B, Ji B, Sun Y, Wang G, Liu J, Zheng Z. Is microplegia really superior to standard blood cardioplegia? The results from a meta-analysis. Perfusion. 2015;30(5):375-82

\section{Publisher's Note}

Springer Nature remains neutral with regard to jurisdictional claims in published maps and institutional affiliations.

Ready to submit your research? Choose BMC and benefit from:

- fast, convenient online submission

- thorough peer review by experienced researchers in your field

- rapid publication on acceptance

- support for research data, including large and complex data types

- gold Open Access which fosters wider collaboration and increased citations

- maximum visibility for your research: over $100 \mathrm{M}$ website views per year

At $\mathrm{BMC}$, research is always in progress.

Learn more biomedcentral.com/submissions 